\title{
Movable-clamp undercutting of sheet metal parts
}

\author{
Vladimir Mironenko \\ Federal State Budget Educational Institution of Higher \\ Education «Irkutsk National Research Technical \\ University» \\ INRTU \\ Irkutsk, Russian Federation \\ mironenko_vv@istu.edu
}

\author{
Shmakov Andrey \\ Federal State Budget Educational Institution of Higher \\ Education «Irkutsk National Research Technical \\ University» \\ INRTU \\ Irkutsk, Russian Federation \\ shmakov@istu.edu
}

\begin{abstract}
The paper analyzes a regulatory document that specifies undercut forming and parameters. We herein show where, according to that document, it is recommended to form such undercuts, and hence dwell upon problems the document fails to tackle. Discussing a standard-undercut part, we demonstrate how and why underforging occurs and propose solving this problem by using movable clamps. We exemplify two model parts to show how movable-clamp forming can produce parts with non-standard undercuts. The paper presents the results of simulation and field experimentation for such model parts. The scheme and the technology of forming with a movable clamp are illuminated. The theoretical component of the shaping of the undercuts and the conditions necessary for eliminating defects during their shaping are described.
\end{abstract}

Keywords— hydroforming, sheet stamping, undercuts.

\section{INTRODUCTION}

Modern-day aircraft engineering is facing serious problems relating to forming undercuts on sheet metal parts. There are multiple options of joining sheet metal parts in an assembly, including overlap joints and butt joints. Overlap joints are simpler in design, ligher, and more rigid compared to butt joints. The main drawback of overlap joints is the need for so-called undercuts. The overlapping length depends on how many fixtures have to be placed to ensure the desired strength. When forming an undercut on the board of a part using the existing equipment, the elastic medium does not provide sufficient pressure resulting in such defects as underforging or corrugation, which is exactly the problem. A butt joint is more convenient to produce, but it is heavier and requires an additional part (lining) [12].

Highly complex manual correction of parts is necessary to eliminate such defects and underforging or corrugation. Local manual correction disrupts the entire part outline, necessitating total manual correction. Manual correction also means one can ignore tooling springing, as manual correction completely alters the shape of the part in its undercut section.

Underforging and corrugation occur due to the excessive apical rigidity of the undercut, which is the case when hydroformed This is due to the geometric shape of the undercut. To overcome such excessive apical rigidity, the pressure of the elastic medium should be applied to an additional tooling component, which will transfer such increased force locally to the undercut apex to create a stressstrain condition similar to uniform compression. The effect of such additional tooling can be maximized by moving it during the forming process. It is the ratio of undercut parameters that gives rise to or excludes the emergence of, a defect. OST 1.52468-80 contains a nomogram (see Fig. 1) that shows the recommendable undercut parameter ratio areas. These graphs show the defect-free undercutting areas for such materials as АМг2М - АМг6М, Д16М, Д19М, В95М, 1201, 1420 with a tool radius $\mathrm{r}=2 \mathrm{~S}$.

The nomogram shows that the forming of an undercut may give rise to three defects: corrugation $(\mathrm{C})$; underforging $(\mathrm{H})$; and breakage $(\mathrm{P})$. This nomogram also presents areas of increased defect probability. The probability of underforging is greater at greater workpiece thicknesses (i.e. lower $\mathrm{h} / \mathrm{S}$ ratios). The probability of corrugation is greater at smaller workpiece thicknesses (i.e. higher $\mathrm{h} / \mathrm{S}$ ratios). The probability of breakages is higher at greater undercut steepness, i.e. greater $\mathrm{h} / \mathrm{l}$ ratios.

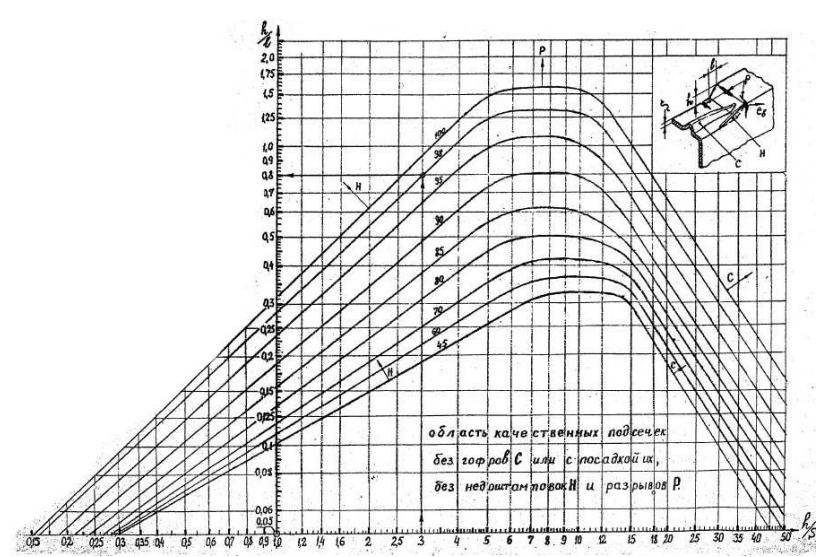

Fig. 1. Maximum steepness of median undercuts for rubber pad forming.

However, when using this nomogram and regulatory documentation, the following problems may rise:

- geometric parameters of the undercut are not within recommendable levels;

- the part material is not on the list in these recommendations;

- correctable defects such as corrugation and underforging might occur under recommended parameters due to a number of non-controllable factors, 
e.g. if the supplied material has different properties. This will necessitate manual correction;

- the machinery does not generate enough pressure to form high-quality undercuts with recommended forming parameters.

\section{PROBLEMS WITH SHEET METAL PARTS UNDERCUT IN ACCORDANCE WITH REGULATORY DOCUMENTATION}

However, even if the undercut parameters are within GOST thresholds, i.e. within the extreme graphs of the nomogram in Fig. 1, it alone does not warrant defect-free production. To prove this statement, we chose a 1163AM sheet part, see Fig. 2. As can be seen from Fig. 2, the undercut parameters are within the defect-free range.
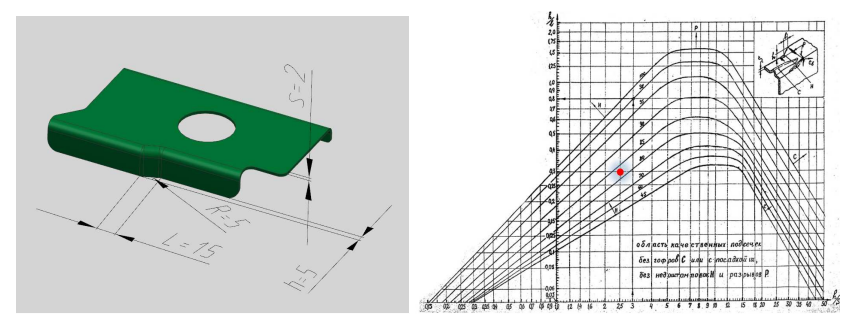

Fig. 2. Standard-undercut part.

To simulate the forming process, we used PAM-STAMP software suit by ESI Group, France.

The 1163AM workpiece material had the following parameters for simulation [4], [21], [22], [23]:

- Young's modulus equaled $70 \mathrm{GPa}$;

- Poisson's ratio equaled 0.33;

- density equaled $2.6 \mathrm{~kg} / \mathrm{mm} 3$;

- anisotropy $\mathrm{r}^{\circ}, \mathrm{r} 45^{\circ}, \mathrm{r} 90^{\circ}$ equaled $0.5089,1.2808$,

0.6654 , respectively [13];

- the plastic part of the flow curve was described by the Krupkowsky law. Functional constants for 1163AM were as follows: $\mathrm{K}=0.32417 \mathrm{GPA}, \mathrm{n}=$ $0.2183,0.0011$.

The hydroforming process was simulated for a pressure of $100 \mathrm{MPa}$, which is the maximum hydroforming pressure with the today's machinery; computing showed a $0.704 \mathrm{~mm}$ undeforming at the undercut apex, see Fig. 3.

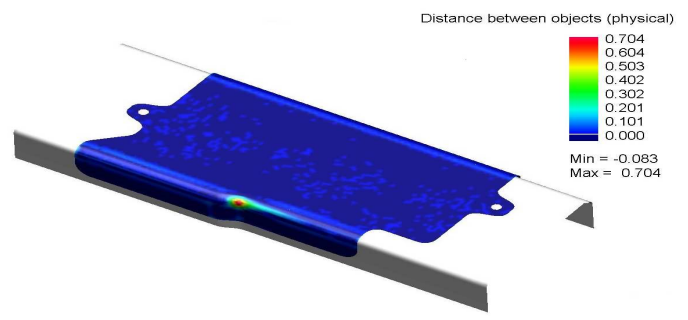

Fig. 3. Modeling a standard-undercut part.
To correct such defects, we propose using an additional tooling component, which is movable clamp. Defects are corrected by pre-hydroforming and movable-clamp postforming. Prior to forming, tooling is mounted upon the press table and is fixed to the sow block with a slot for movable components; the workpiece is mounted onto the tooling studs and is pre-formed; then the movable clamp is mounted in the sow-block slots and is used for post-forming, which is how high-quality undercut parts are produced [11].

The elastic medium affects the sloped surfaced of the clamp and moves it along the inclined surface of sow-block slots, see Fig. 4. Moving the clamp during the post-forming process creates the necessary stress-strain state and generates enough force to be applied to the deformable part of the workpiece, which excludes underforging.

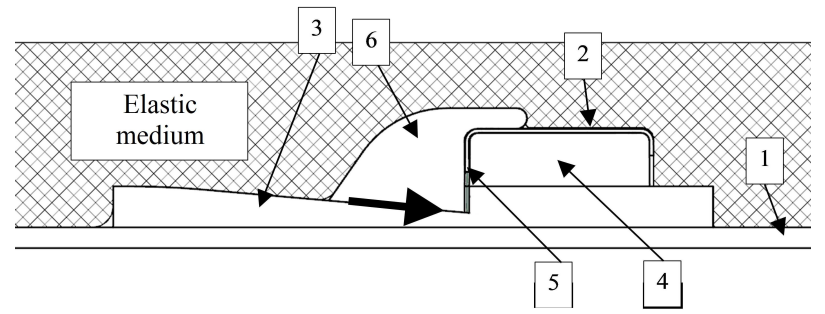

1 is the press table; 2 - the positioning pins;

3 is the sow block; 4 is the forming tooling;

5 is the workpiece (developed); 6 is the movable clamp;

Fig. 4. Places where the elastic medium affects the movable clamp; the basic forming-force vector.

Modeling the process in accordance with this technology resulted in a less-than- $0.1 \mathrm{~mm}$ underforging, hence the defect was successfully corrected, see Fig. 5. See Fig. 6 for the movable-clamp and sow-block model. Fig. 6 also shows how the movable clamp moves in the sow block during the forming process.

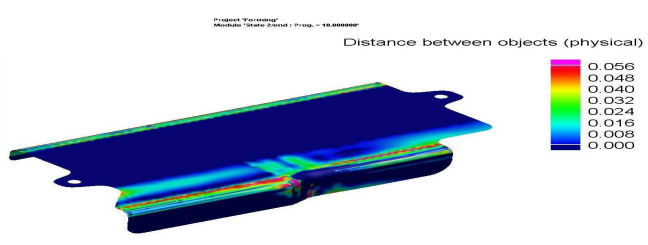

Fig. 5. Results of modeling a standard-undercut part, using a movable clamp.
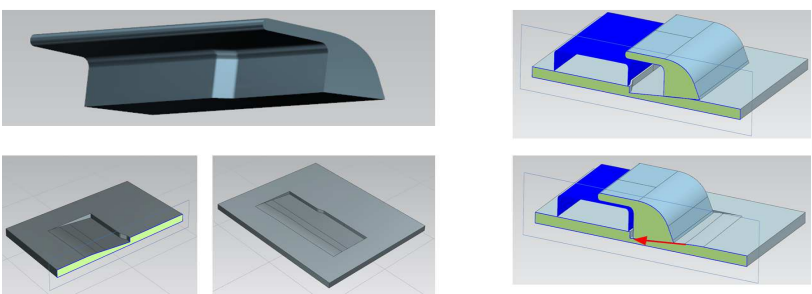

Fig. 6. Movable clamp, sow block, and movable-clamp motion vector. 
Based on the modeling results, we carried out a field experiment which produced three defect-free parts, see Fig. 7.

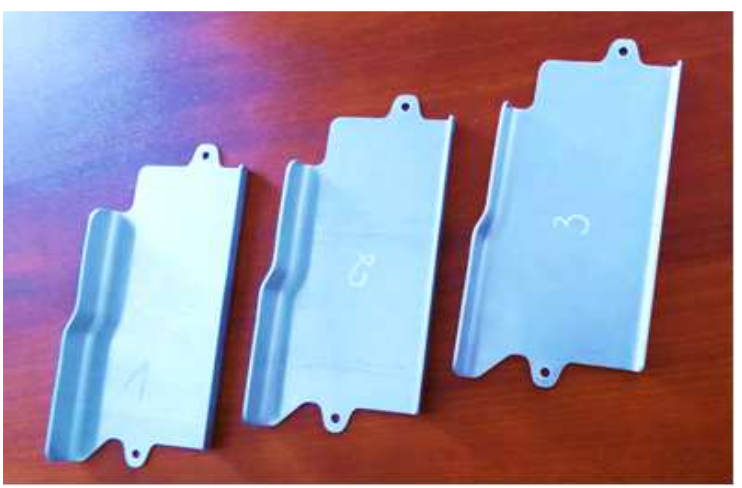

Fig. 7. Produced standard-undercut parts.

Measuring the underforging [28], [29] with a CMM probe where the inclined undercut becomes flat showed that the deviations of real parts from their respective digital models were within acceptable levels, see TABLE I.

TABLE I. PART MEASUREMENTS

\begin{tabular}{|c|c|c|c|}
\hline \multirow{2}{*}{$\begin{array}{c}\text { Part No. } \\
\text { (Pressure } \\
\text { MPa) }\end{array}$} & \multicolumn{2}{|c|}{$\begin{array}{c}\text { Simulation for 100 MPa with the } \\
\text { given tooling }\end{array}$} & \multirow{2}{*}{$\begin{array}{c}\text { Experimental } \\
\text { test }\end{array}$} \\
\cline { 2 - 4 } & no clamp & movable clamp & \\
\hline $1(60)$ & & & 0.092 \\
\hline $2(80)$ & \multirow{2}{*}{0.704} & 0.056 & 0.071 \\
\hline $3(80)$ & & & 0.065 \\
\hline
\end{tabular}

Therefore, this technology can produce quality defect-free parts.

\section{FORMING MODEL PARTS}

The proposed movable-clamp forming technology proved feasible for standard undercuts. However, it has a much higher potential. Its applications go far beyond the nomogram shown in Figure 1. To prove this hypothesis, we generated undercut part models that went beyond the regulatory nomogram values, see Fig. 8, Fig. 9.
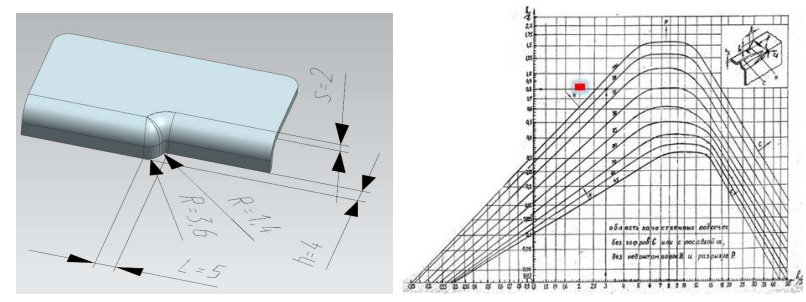

Fig. 8. Part 1, thick, low undercut runout.
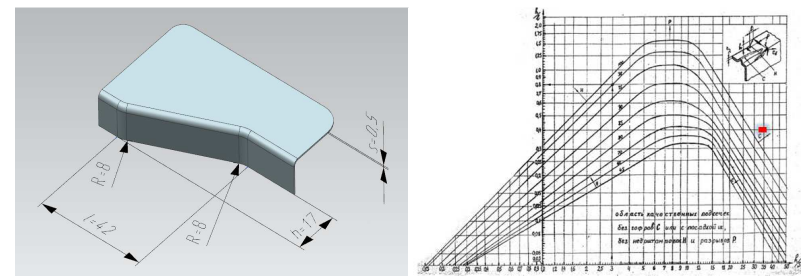

Fig. 9. Part 2, thin, high undercut runout

For Part 1, we produced tooling, a movable clamp, and a sow block, see Fig. 10. We also simulated the process by means of the ESI Group PAM-STAMP 2G software suit, using the same material parameters as for the standardundercut part, i.e. material 1163 AM, see Fig. 11. Simulation was done for various pressures corresponding to that of a laboratory machine and that of the QFC $1.2 \times 3-1000$ industrial press.

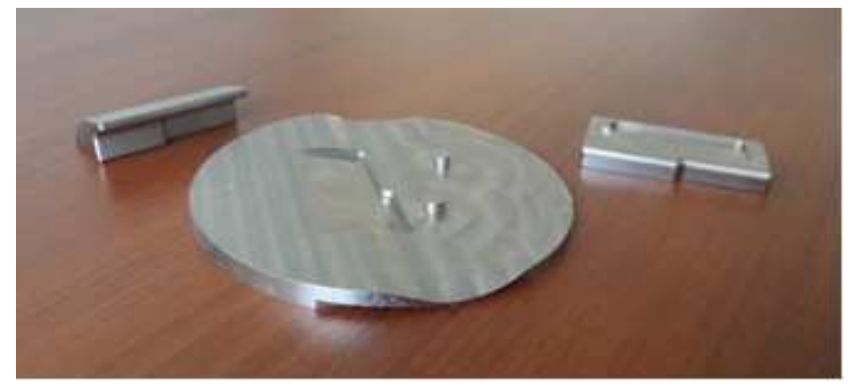

Fig. 10. Sow block, movable clamp, and tooling for Part 1.
$30 \mathrm{MPa}$

Laboratory machine, no movable clamp

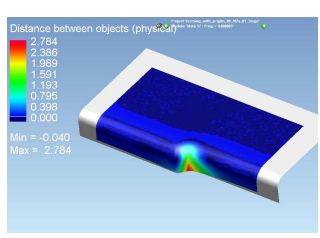

Maximum underforging $2.784 \mathrm{~mm}$.

(a)
$100 \mathrm{MPa}$ QFC 1.2x3 -1000 industrial press, no movable clamp

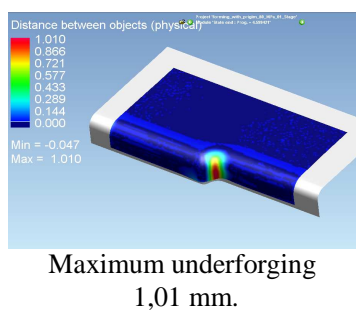

(b)
$30 \mathrm{MPa}$

Laboratory machine, movable clamp

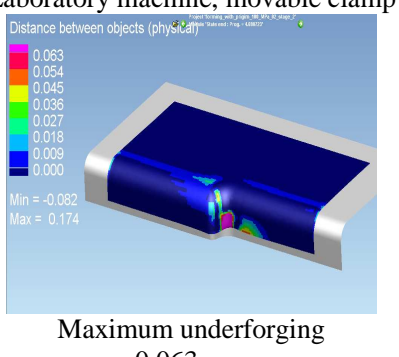

$0.063 \mathrm{~mm}$.

(c)

Fig. 11. Part 1 simulation results. 
As shown in Fig. 11, a and Fig. 11, b, the underforging of the model Part 1 occurred when using no movable clamps; greater pressure reduced underforging but didn't solve the problem. However, as can be seen in Fig. 11, c, using a movable clamp completely eliminates underforging even at low pressure.

For Part 2, we produced tooling, a movable clamp, and a sow block, see Figure 12. We also simulated the process by means of the ESI Group PAM-STAMP $2 \mathrm{G}$ software suit, using the same material parameters as for the standardundercut part, i.e. material 1163 AM, see Figure13.

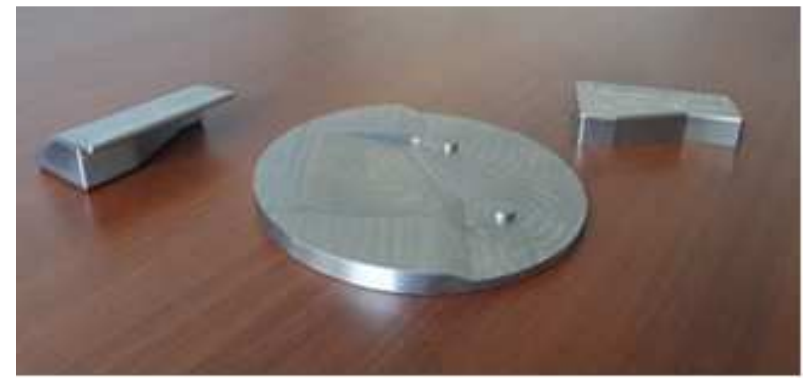

Fig. 12. Sow block, movable clamp, and tooling for Part 2.

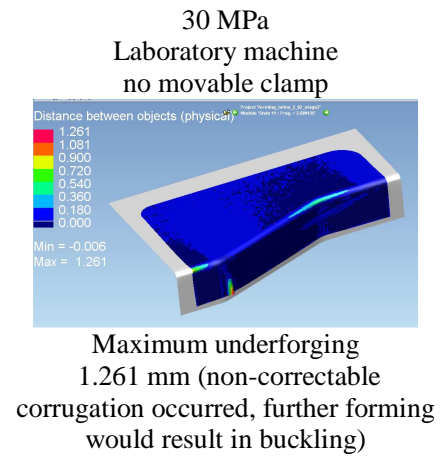

(a)

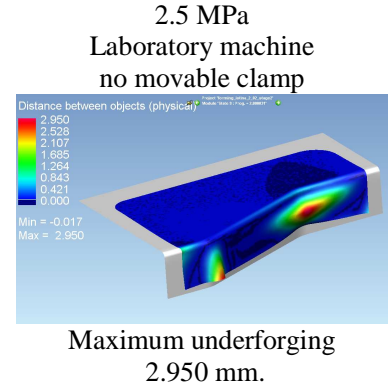

(b)
$30 \mathrm{MPa}$

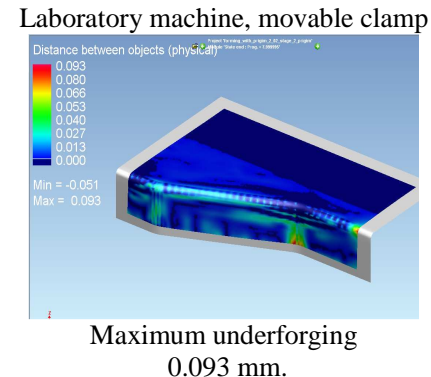

(c)

Fig. 13. Part 2 simulation results

As can be seen from Fig. 13, a, corrugation is not a problem soluble by greater pressures. On the contrary, greater pressures may cause a high corrugation, which may become unstable and result in buckling. Using a movable clamp in this high-corrugation situation destabilizes the process as all the force is applied to a small-area apex, which again may result in buckling. To avoid this situation, first-stage pressure has to be minimized for undercuts with such parameters, see Fig. 13, b. At lower pressures, corrugation is of a more consistent shape for shrinking. Further movable-clamp forming can correct this defect, see Fig. 13, c.

We caried out field experiements using the tooling we had produced as well as the results of our finite-element analysis. The results were fully repeatable, see TABLE II. This again proves the movable-clamp technology feasible.

TABLE II. RESULTS OF FIELD EXPERIMENTS

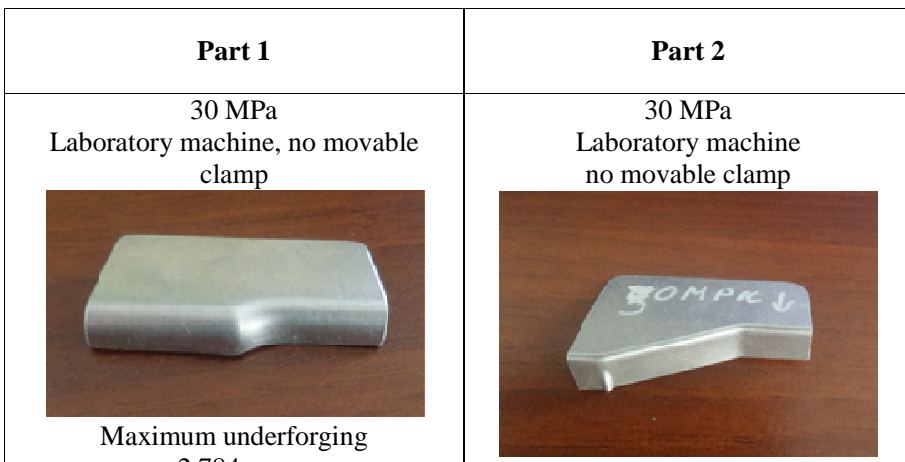
$2.784 \mathrm{~mm}$.

Maximum underforging

$1.261 \mathrm{~mm}$ (non-correctable corrugation occurred, further forming would result in buckling)

QFC 1.2x3 -1000 industrial press, no movable clamp

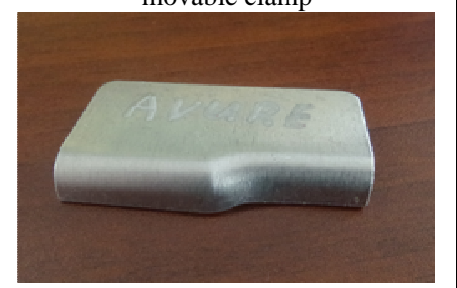

Maximum underforging 1,01 mm.

Maximum underforging $2.950 \mathrm{~mm}$.

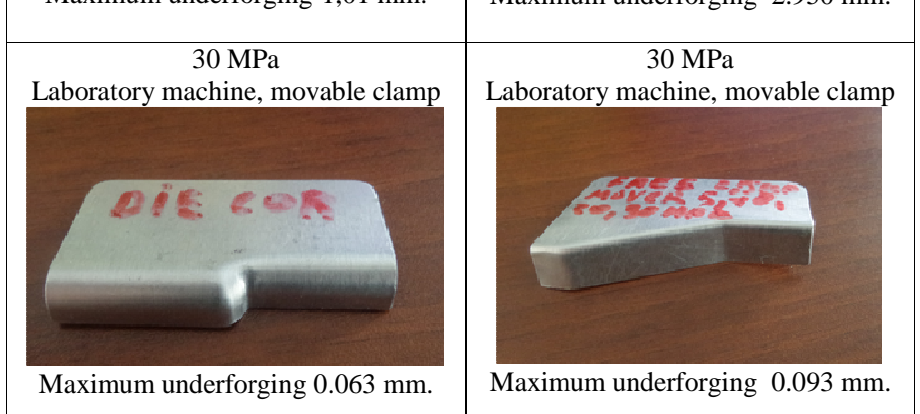

\section{CONCLUSIONS}

We have therefore discovered a movable-clamp undercutting technology that can consistently produce defectfree parts with standard or sub-/super-standard undercuts. We have applied to patent this technology, see app. no. 2017142652. 


\section{References}

[1] I. Bobarika, A. Demidova, S. Bukhanchenko, "Hydraulic Model and Algorithm for Branched Hydraulic Systems Parameters Optimization // PROCEDIA ENGINEERING“, Ser. "International Conference on Industrial Engineering, ICIE 2017". pp. 1522-1527, 2017.

[2] S. SHAHRAI, N. SHARYPOV, P POLYAKOV, V.KONDRATIEV, A. KARLINA, "QUALITY OF ANODE. OVERVIEW OF PROBLEMS AND SOME METHODS OF THEIR SOLUTION PART 2. IMPROVING THE QUALITY OF THE ANODE” INTERNATIONAL JOURNAL OF APPLIED ENGINEERING RESEARCH, vol. 21, pp. 11268-11278, 2017.

[3] A. BARANOV, V. KONDRATIEV, V. ERSHOV, A. JUDIN, N. YANCHENKO, "IMPROVING THE EFFICIENCY OF ALUMINIUM PRODUCTION BY APPLICATION OF COMPOSITE CHROME PLATING ON THE ANODE PINS", INTERNATIONAL JOURNAL OF APPLIED ENGINEERING RESEARCH, vol. 22, pp. 10907-10911, 2016.

[4] A. Cheslavskaya, V. Mironenko, A. Kolesnikov, N. Maksimenko, V. Kotov, "CHOOSING AN EFFICIENT METHOD FOR FORMING PARTS BY MEANS OF AN ENGINEERING ANALYSIS PERFORMED WITH THE USE OF A CAE SYSTEM", Metallurgist, vol. 58, issue 11-12. pp. 1051-1059, 2015.

[5] R. KHUSAINOV, A. SABIROV, I. MUBARAKSHIN, "STUDY OF DEFORMATIONS FIELD IN THE WORKING ZONE OF VERTICAL MILLING MACHINE", PROCEDIA ENGINEERING Ser. "International Conference on Industrial Engineering, ICIE 2017", pp. 1069-1074, 2017.

[6] R. FABÍK, J. KLIBER, T. KUBINA, I. MAMUZIC, S. AKSENOV "MATHEMATICAL MODELLING OF FLAT AND LONG HOT ROLLING BASED ON FINITE ELEMENT METHODS (FEM)", METALURGIJA (SISAK, YUGOSLAVIA), vol. 51, issue 3, pp. 341344, 2012.

[7] E. CHUMACHENKO, S. AKSENOV, I. LOGASHINA, "OPTIMIZATION OF SUPERPLASTIC FORMING TECHNOLOGY" METAL 2012 - CONFERENCE PROCEEDINGS, 21ST INTERNATIONAL CONFERENCE ON METALLURGY AND MATERIALS, pp. 295-301, 2012.

[8] B. MOKRITSKII, V. VERESHCHAGIN, E. MOKRITSKAYA, S. PYACHIN, S.BELYKH, A.VERESHCHAGIN, "COMPOSITE HARDALLOY END MILLS", RUSSIAN ENGINEERING RESEARCH, vol. 36 , issue 12, pp. 1030-1032, 2016

[9] V. Kondrat'ev, E. Rzhechitskij, S. Shakhrai, A. Karlina, I. Sysoev "RECYCLING OF ELECTROLYZER SPENT CARBON-GRAPHITE LINING WITH ALUMINUM FLUORIDE REGENERATION", Metallurgist, vol. 60, issue 5-6, pp. 571-575, 2016.

[10] V. Kondrat'ev, A. Govorkov, M. Lavrent'eva, I. Sysoev, A. Karlina, "Description of the heat exchanger unit construction, created in IRNITU”, International Journal of Applied Engineering Research, vol. 11, issue 19, pp. 9979-9983, 2016.

[11] G. Sevastyanov, V. Chernomas, S. Marin, A. Sevastyanov, "NUMERICAL SIMULATION FEATURES OF CONTINUOUS CASTING PROCESS FORM AD31 (A(GREEK PASSAGE)31) ALLOY USING FINITE-DIFFERENCE AND FINITE-ELEMENT MODELS", Non-Ferrous Metals, vol. 2015, issue 2, pp. 25-29, 2015.

[12] S. Belykh, A. Perevalov, "MODELLING OF BENDING ROLLS OF EXTRUDED NONSYMMETRIC IN THE MSC MARC", European Researcher, vol. 5-1 (48), pp. 1140-1146, 2013.

[13] V. Roshchupkin, R. Krupskii, T. Levchuk, N. Semashko, "METHODICAL ASPECTS OF EXCITING ACOUSTIC EMISSION OF MAGNETOSTRICTION", Russian metallurgy (Metally), vol. 4, pp. 361-362, 2002.

[14] V. Roshchupkin, N. Semashko, R. Krupskii, A. Kupov, V. Shport, "TEMPERATURE AND STRAIN CHANGES IN VT20 TITANIUM ALLOY UNDER ELECTRIC-PULSE EFFECT", High Temperature,. vol. 41, issue 5, pp. 633-638, 2003.

[15] M. Pokrasin, N. Semashko, R. Krupskii, A. Kupov, "EFFECT OF ELECTRIC-PULSE TREATMENT ON THE DISLOCATION
STRUCTURE OF OT4 TITANIUM ALLOY", Russian metallurgy (Metally), vol. 2004, issue 6, pp. 595-600, 2004.

[16] V. Roshchupkin, M. Pokrasin, A. Chernov, N. Sobol, N. Semashko, R. Krupskii, A. Kupov, "DEFORMATION OF VT20 AND OT4 TITANIUM ALLOYS SUBJECTED TO A HIGH-DENSITY PULSE CURRENT DURING STATIC LOADING", Russian metallurgy (Metally), vol. 2005, issue 4, pp. 350-354, 2005.

[17] Y. Erisov, F. Grechnikov, S. Surudin, "YIELD FUNCTION OF THE ORTHOTROPIC MATERIAL CONSIDERING THE CRYSTALLOGRAPHIC TEXTURE", Structural Engineering and Mechanics, vol. 58, issue 4, pp. 677-687, 2016.

[18] Y. Erisov, S. Surudin, A. Shlyapugin, F. Grechnikov, "THE END-TOEND COMPUTER SIMULATION OF CASTING AND SUBSEQUENT METAL FORMING”, Key Engineering Materials, vol. 685, pp. 167-171, 2016.

[19] V. Mikheev, S. Surudin, "THE RESULTS COMPARASION OF CALCULATION METHOD AND COMPUTER MODELING OF DOUBLE CURVATURE SHEET SHELLS IN STRETCH FORMING PROCESS”, Key Engineering Materials, vol. 684, pp. 21-28, 2016.

[20] V. Mikheev, S. Smolnikov, S. Surudin, D. Savin, "STATISTICAL ANALYSIS OF STRETCH SHAPING PROCESS OF BICONVEX SKIN", Russian Aeronautics, vol. 59, issue 1, pp. 145-150, 2016.

[21] A. Ershov, Y. Loginov, "USE OF THE PROGRAM PAM-STAMP TO STUDY THE EFFECT OF THE AS-RECEIVED CONDITION OF A MATERIAL ON ITS FORMABILITY DURING STAMPING", Metallurgist, vol. 58, issue 3-4, pp. 162-166, 2014.

[22] A. Ershov, V. Kotov, Y. Loginov, "CALCULATION OF THE COMPENSATION OF A STAMPING TOOL AFTER SPRINGBACK IN THE SOFTWARE PACKAGE PAM-STAMP”, Metallurgist, vol. 56, issue 7-8, pp. 477-481, 2012.

[23] A. Ershov, V. Kotov, Y. Loginov, "MODELING THE FORMATION OF AUTOMOBILE BODY PANELS BY AN ELASTIC PUNCH IN THE SOFTWARE PACKAGE PAM-STAMP 2G', Metallurgist, vol. 56, issue 9-10, pp. 647-651, 2013.

[24] Y. Loginov, V. Kotov, V. Solovei, “TRANSFORMATION OF THE YIELDING CONDITION DURING THE DEFORMATION OF HCP METALLIC MATERIALS", Russian metallurgy (Metally), vol. 2010, issue 3, pp. 235-240, 2010.

[25] Y. Loginov, M. Puzanov, A. Uritskii, "REDUCING THE EDGE DEFORMATION OF THIN ELECTRICAL STEEL SHEET”, Steel in Translation, vol. 47, issue 4, pp. 267-273, 2017.

[26] B. Kamenetskii, Y. Loginov, N. Kruglikov, "POSSIBILITIES OF A NEW COLD UPSETTING METHOD FOR INCREASING MAGNESIUM PLASTIFICATION", Russian Journal of Non-Ferrous Metals, vol. 58, issue 2, pp. 124-129, 2017.

[27] L. Mal'tseva, A. Levina, Y. Loginov, T. Mal'tseva, S. Demidov, M. Khadyev, S. Gladkovskii, "CHANGES IN THE STRUCTURE AND PROPERTIES UNDER DEFORMATION OF AUSTENITICFERRITIC STEEL AT ROOM AND NEGATIVE TEMPERATURES", Metal Science and Heat Treatment, vol. 57, issue 11, pp. 645-651, 2016.

[28] Rusakov G., Illarionov A., Loginov Y., Lobanov M., Redikul'tsev A., "INTERRELATION OF CRYSTALLOGRAPHIC ORIENTATIONS OF GRAINS IN ALUMINUM ALLOY AMG6 UNDER HOT DEFORMATION AND RECRYSTALLIZATION", Metal Science and Heat Treatment, vol. 56, issue 11-12, pp. 650-655, 2015.

[29] P. Pal-Val, V. Natsik, L. Pal-Val, Y. Loginov, S. Demakov, A. Illarionov, "UNUSUAL YOUNG'S MODULUS BEHAVIOR IN ULTRAFINE-GRAINED AND MICROCRYSTALLINE COPPER WIRES CAUSED BY TEXTURE CHANGES DURING PROCESSING AND ANNEALING", Materials Science and Engineering: A, vol. 618, pp. 9-15, 2014.

[30] S. Bourkine, E. Korshunov, Y. Loginov, E. Shakhapazov, A. Nassibov, N. Babailov, "PROJECTION OF STEEL WIRE PRODUCING TECHNOLOGY BEYOND THE CONTINUOUS-CASTING OF AN INGOT USING A DIRECT COMBINATION OF CASTING AND METAL FORMING”, Journal of Materials Processing Technology, vol. 86 , issue $1-3$, pp. 278-290, 1999. 